\title{
Pattern Recognition Analysis of Proton Nuclear Magnetic Resonance Spectra of Extracts of Intestinal Epithelial Cells under Oxidative Stress
}

\author{
Keiji Nakata', Norio Sato ${ }^{2}$, Keiko Hirakawa ${ }^{3}$, Takayuki Asakura', \\ Takao Suzuki², Ran Zhu', Takeshi Asano ${ }^{5}$, Kaoru Koike², \\ Youkichi Ohno ${ }^{3}$ and Hiroyuki Yokota ${ }^{1}$ \\ ${ }^{1}$ Department of Emergency and Critical Care Medicine, Nippon Medical School \\ ${ }^{2}$ Department of Primary Care and Emergency Medicine, Kyoto University \\ ${ }^{3}$ Department of Legal Medicine and NMR Laboratory, Nippon Medical School \\ ${ }^{4}$ Department of Critical Care Medicine, 1st Affiliated Hospital of China Medical University, China \\ ${ }^{5}$ Department of Pediatrics, Nippon Medical School
}

\begin{abstract}
Background: Mesenteric ischemia-reperfusion induces gut mucosal damage. Intestinal mucosal wounds are repaired by epithelial restitution. Although many different molecular mechanisms have been shown to affect cell metabolism under oxidative conditions, these molecular mechanisms and metabolic phenotypes are not well understood. Nuclear magnetic resonance (NMR) spectroscopic data can be used to study metabolic phenotypes in biological systems. Pattern recognition with multivariate analysis is one chemometric technique. The purpose of this study was to visualize, using a chemometric technique to interpret NMR data, different degrees of oxidant injury in rat small intestine (IEC-6) cells exposed to $\mathrm{H}_{2} \mathrm{O}_{2}$.

Methods: Oxidant stress was induced by $\mathrm{H}_{2} \mathrm{O}_{2}$ in IEC- 6 cells. Cell restitution and viability were assessed at different $\mathrm{H}_{2} \mathrm{O}_{2}$ concentrations and time points. Cells were harvested for pattern recognition analysis of ${ }^{1} \mathrm{H}-\mathrm{NMR}$ data.

Results: Cell viability and restitution were significantly suppressed by $\mathrm{H}_{2} \mathrm{O}_{2}$ in a dosedependent manner compared with control. Each class was clearly separated into clusters by partial least squares discriminant analysis, and class variance was greater than $90 \%$ from 2 factors.

Conclusion: Pattern recognition of NMR spectral data using a chemometric technique clearly visualized the differences of oxidant injury in IEC-6 cells under oxidant stress.

(J Nippon Med Sch 2014; 81: 236-247)
\end{abstract}

Key words: pattern recognition, partial least squares discriminant analysis, nuclear magnetic resonance, oxidant stress

Correspondence to Norio Sato, Department of Primary Care and Emergency Medicine, Kyoto University, 54 Kawaramachi, Shogoin, Sakyoku, Kyoto 606-8507, Japan

E-mail: drnori@kuhp.kyoto-u.ac.jp

Journal Website (http://www.nms.ac.jp/jnms/) 


\section{Introduction}

Intestinal ischemia-reperfusion (I/R) injury is often seen after hemorrhagic shock, septic shock, and small-bowel transplantation. It causes histological evidence of mucosal injury and physiological evidence of loss of normal digestive and barrier functions, which can lead to development of postinjury multiple organ dysfunction syndrome ${ }^{1}$. I/ $\mathrm{R}$ injury is the tissue damage that is caused when blood supply returns to the tissue after a period of ischemia. Because of the absence of oxygen supplied by blood during the ischemic period, the restoration of circulation results in inflammation and oxidative damage through the induction of oxidative stress.

In experimental models used to investigate oxidative stress responses of cells, cultured cells are often exposed to hydrogen peroxide $\left(\mathrm{H}_{2} \mathrm{O}_{2}\right)$ added to the culture medium ${ }^{23}$. IEC-6 cells are derived from normal rat intestine, are nontumorigenic, and retain the undifferentiated character of epithelial stem cells ${ }^{4}$. These cells are a well-studied in vitro model of restitution following mechanical injury to cell monolayers ${ }^{5,6}$. Scraped wounding was used as an in vitro model of injury that mimics the early celldivision-independent stages of epithelial restitution.

Studies in vitro and in vivo indicate that healing of superficial damage to the mucosa occurs by rapid migration of normal adjacent intestinal epithelial cells over the denuded area, with reestablishment of epithelial continuity and integrity, a process termed restitution. The repair process is regulated in a cellspecific manner by various growth factors, cytokines, peptides, and matrix components ${ }^{7-9}$. Many different molecular mechanisms have also been shown to influence cell metabolism with upregulation or down-regulation of target genes, enzymes, and functional proteins under oxidative conditions. However, these molecular mechanisms and metabolic phenotypes are not well understood.

Nuclear magnetic resonance (NMR) spectroscopic data can be used to study metabolic phenotypes in biological systems ${ }^{10}$. Chemometrics is a chemical discipline that uses mathematics, statistics, and formal logic to design or select optimal experimental procedures, to provide maximum relevant chemical information by analyzing chemical data, and to obtain knowledge about chemical systems ${ }^{11}$. Pattern recognition with multivariate analysis is one chemometrics technique. The goal of this study was to visualize different degrees of oxidant injury in IEC-6 cells exposed to $\mathrm{H}_{2} \mathrm{O}_{2}$ by using a chemometric technique to interpret NMR data.

\section{Materials and Methods}

\section{Cell Preparation and Reagents}

IEC-6 cells purchased from the American Tissue Culture Collection (Manassas, VA, USA) were maintained in Dulbecco's modified Eagle's medium supplemented with $4 \mathrm{mM}$ L-glutamine, $4,500 \mathrm{mg} / \mathrm{L}$ glucose, $1,500 \mathrm{mg} / \mathrm{L}$ sodium bicarbonate, $10 \%$ fetal bovine serum, $0.1 \mathrm{U} / \mathrm{mL}$ insulin (Sigma-Aldrich, St. Louis, MO, USA), and 1\% streptomycin (Gibco BRL, Gaithersburg, MD, USA). Cells were cultured in a humidified incubator with an atmosphere of $5 \% \mathrm{CO}_{2}$ at $37^{\circ} \mathrm{C}$ and were given fresh medium every 2 days. Hydrogen peroxide was purchased from Wako Pure Chemicals (Osaka, Japan), and 0.4\% trypan-blue stain was purchased from Invitrogen (Carlsbad, CA, USA).

\section{Experiment 1. Different Dose Responses}

\section{Following Oxidant Stress on IEC-6 Cells}

The IEC-6 cells were cultured to confluence then subjected to oxidant stress induced by $\mathrm{H}_{2} \mathrm{O}_{2}$ (control, $0.25 \mathrm{mM}, 0.5 \mathrm{mM}$ ) for 24 hours. Cell migration and cell viability were assessed. Cells were harvested after 24 hours for pattern recognition of NMR spectra.

\section{Experiment 2. Different Time Points Following Oxidant Stress on IEC-6 Cells}

IEC-6 cells were cultured to confluence, and then oxidant stress was induced by $\mathrm{H}_{2} \mathrm{O}_{2}(0.5 \mathrm{mM})$. Cell migration was assessed. Cells were harvested after 6,12 , and 24 hours for pattern recognition of NMR spectra.

\section{Wound Restitution Measurement}

The restitution of IEC-6 cells was measured with a modified version of a previously described 
technique ${ }^{12,13}$. The IEC-6 cells were plated in 6-well polystyrene plates to reach confluence in normal growth medium. A denuded epithelial wound was created in a standardized fashion by scraping the IEC-6 monolayers with a plastic blade. After being scraped, the wounded monolayers were washed, and complete medium was then added. Wound areas were viewed under a microscope at various times after scrape wounding and were photographed with a microscope equipped with a camera (Spot Insight, Spot Imaging Solutions, Sterling Heights, MI, USA). The mean restitution length was calculated as the migration area as a region of interest.

\section{Cell Viability}

Cell viability was measured with a trypan blue dye exclusion assay, as has been described previously ${ }^{14}$. Briefly, cells were grown to confluence and incubated with different concentrations of $\mathrm{H}_{2} \mathrm{O}_{2}$. Viable cells and nonviable cells were counted after trypan blue staining. The percentage of viable cells was calculated as $100 \times$ (number of viable cells)/ (total number of cells).

\section{Sample Preparation}

Cells were grown to confluence and incubated with different concentrations and times of $\mathrm{H}_{2} \mathrm{O}_{2}$ exposure. Cells were washed twice in cold phosphate-buffered saline, collected with a scraper on the attached cells, and stored at $-80^{\circ} \mathrm{C}$ until further analysis. Neutral extraction was performed according to the protocol of Yoshioka ${ }^{15}$. The basic extraction method was designed by Folch ${ }^{16}$ and was originally designed for extraction of total lipids from animal tissues. However, this method is also useful for extracting polar organic compounds together, separately from nonpolar lipids and essentially without any in vitro modifications. The frozen cells were crushed and mixed thoroughly in $1.5 \mathrm{~mL}$ of a 2 : 1 chilled chloroform : methanol mixture. The mixture was extracted and separated with an extractive device (Centractor ${ }^{\mathrm{TM}}$, Uniflows, Tokyo, Japan). The mixture was spun in a centrifuge at 3,000 revolutions per minute (rpm) for 10 minutes. A total of $0.5 \mathrm{~mL}$ of distilled water was added to the mixture and then extracted under the same conditions described above. The mixture was separated into 2 layers of solutions and insoluble residues. Finally, the extract was centrifuged at $3,000 \mathrm{rpm}$ for 5 minutes, and the upper phase solution was evaporated in an evacuated centrifuge for 3 hours. Dried extracts were reconstituted in $180 \mathrm{uL}$ of deuterium oxide $\left(\mathrm{D}_{2} \mathrm{O}\right)$ (ISOTEC, SigmaAldrich) and pipetted into 3-mm NMR tubes (Wilmad-LabGlass, Vineland, NJ, USA). The tubes were placed in 5-mm NMR tubes (Wilmad-LabGlass) that contained $300 \mu \mathrm{L}$ of $\mathrm{D}_{2} \mathrm{O}$ containing $25 \mu \mathrm{M}$ sodium (3-trimethylsilyl) tetradeuteriopropionate2,2,3,3-d $\mathrm{d}_{4}$ (TMSP) (MSD Isotopes, Montreal, Canada) for subsequent NMR measurements. The $\mathrm{D}_{2} \mathrm{O}$ provided a deuterium field frequency lock for the NMR spectrometer, while TMSP provided an internal chemical shift reference $(\delta=0.00)$.

Chemical shift $\delta(\mathrm{ppm}) \times 10^{-6}$

$=$ difference between a resonance frequency and that of a reference substance (Hz) operating frequency of the spectrometer $(\mathrm{Hz})$

\section{Acquisition of Proton Nuclear Magnetic Resonance Data}

Solution state ${ }^{1} \mathrm{H}$ NMR spectroscopy was performed at a proton resonance frequency of 300 $\mathrm{MHz}$ using a ECX NMR spectrometer interfaced with a TH5 probe equipped with an automatic 16position sample changer and with Delta ${ }^{\mathrm{TM}}$ NMR processing and control software (version 4.3.2) (JEOL Ltd., Tokyo, Japan).

The ${ }^{1} \mathrm{H}$ NMR spectra were acquired automatically at a probe temperature of $23^{\circ} \mathrm{C}$ using the macro program in Delta ${ }^{\mathrm{TM}}$ systems for automatic measurement supplied by JEOL. The observation range of the NMR signal was $4,500 \mathrm{~Hz}$. The water resonance was suppressed with a conventional presaturation pulse sequence for water (HDO) proton signal suppression based on homogated irradiation and the delays alternating with nutation for tailored excitation (DANTE) pulse sequence (presaturation time $=2$ seconds, dante pulse $=8$ microseconds, DANTE interval $=0.1$ milliseconds, DANTE loop $=185$, ante attenuator $=24 \mathrm{~dB}$ ). CarrPurcell-Meiboom-Gill (CPMG) spin-echo spectra were measured with a spin-echo loop time of 19.2 
milliseconds, a relaxation delay of 2.0 seconds, and 8,000 transients.

\section{Data Processing and Reduction}

The resultant spectra were processed with Alice2 ${ }^{\mathrm{TM}}$, ver. 5.5 (JEOL DATUM Ltd., Tokyo, Japan). Free induction decays were subjected to an exponential weighting function of $0.1 \mathrm{~Hz}$, Fourier transformed from the time to the frequency domain, phased manually, and followed by linear baseline correction and referencing to the TMSP singlet at $0.00 \mathrm{~Hz}$ (chemical shift value $=0.00 \mathrm{ppm}$ ).

The signal intensity distribution of ${ }^{1} \mathrm{H}$ NMR spectral data of each cell was calculated with an macro program written within the Alice2 software for Metabolome $^{\mathrm{TM}}$, ver. 1.0 (JEOL DATUM Ltd.) software package, which integrated the spectral data between $150 \mathrm{~Hz}(0.5 \mathrm{ppm})$ and $2,850 \mathrm{~Hz} \quad(9.5$ ppm) into 225 segments (bins) with $12-\mathrm{Hz}(0.04 \mathrm{ppm})$ integral regions. Spectral regions containing resonances of residual water $(1,380 \mathrm{~Hz}$ [4.6 ppm] to $1,500 \mathrm{~Hz}[5.0 \mathrm{ppm}])$ were excluded before integration. Different bin sizes can reveal different features of the data. Depending on the actual data distribution and the goals of the analysis, different bin widths may be appropriate, so experimentation is usually needed to determine an appropriate width. Finally, all the spectral data were reduced into 174 bins, and to account for the bulk mass differences between samples, each spectral region was normalized to the sum of all of the integrals of each bin.

\section{Multivariate Analysis}

The calculated results obtained from all measured spectra were exported to a spreadsheet as a text file that was used as the input into a pattern recognition/multivariate statistics software package (Unscrambler $\mathrm{X}^{\mathrm{TM}}$ version 10.2, Camo Software AS, Oslo, Norway). Datasets were imported, and partial least squares discriminant analysis (PLS-DA) was performed ${ }^{17.18}$. In brief, PLS-DA with cross-validation was performed to investigate the relationship between different classes. PLS models use both the $\mathrm{x}$ - and $\mathrm{y}$-matrices simultaneously to find the latent variables in $\mathrm{x}$ that best predict the $\mathrm{y}$. In other words, PLS-DA was performed to sharpen the separation between groups by rotating components for principal components analysis with the goal of finding a maximum separation. In this study PLSDA was performed between the spectral profiles and experimental classes, such as concentration and different time points. Each PLS-DA score plot has a correlation loading profile, which helps identify the spectral regions responsible for the observed sample clustering. The horizontal axis in correlation loadings represents chemical shift, and the vertical axis represents contribution degree. Positive contribution areas and negative contribution areas in correlation loadings have an opposite power to separate the plus or minus direction in the score plot.

\section{Statistical Analysis}

Data are expressed as mean \pm SEM. Data were analyzed with one-way analysis of variance, and individual group means were compared by means of Tukey's multiple-group comparison tests. $\mathrm{P}$ values $<0.05$ were considered to indicate significance. Means with different letters are significantly different.

\section{Results}

\section{Experiment 1.}

Effect of different concentrations of $\mathrm{H}_{2} \mathrm{O}_{2}$ on IEC-6 cells wound restitution

Restitution (Fig. 1) was significantly suppressed by $\mathrm{H}_{2} \mathrm{O}_{2}$ at $0.25 \mathrm{mM}(33.1 \pm 2.0 \mu \mathrm{m})$ and by $\mathrm{H}_{2} \mathrm{O}_{2}$ at 0.5 $\mathrm{mM}(19.8 \pm 1.5 \mu \mathrm{m})$ in a dose-dependent manner compared with control $(40.8 \pm 3.4 \mu \mathrm{m})$.

Effect of different concentrations of $\mathrm{H}_{2} \mathrm{O}_{2}$ on IEC-6 cell viability

Cell viability (Fig. 2) was significantly decreased by $\mathrm{H}_{2} \mathrm{O}_{2}$ at $0.25 \mathrm{mM}(88.1 \% \pm 1.2 \%)$ and $\mathrm{H}_{2} \mathrm{O}_{2}$ at $0.5 \mathrm{mM}$ $(68.1 \% \pm 2.3 \%)$ in a dose-dependent manner compared with control $(95.4 \% \pm 1.0 \%)$.

Visualization of ${ }^{1} \mathrm{H}$ NMR spectral data of IEC-6 cells exposed to different concentrations of $\mathrm{H}_{2} \mathrm{O}_{2}$ using PLS-DA analysis

The PLS-DA score plot is shown in Figure 3A. Each dot on the score plot represents the score of factor 1 or of factor 2 of the ${ }^{1} \mathrm{H}$ NMR spectral data of the IEC- 6 cell extract calculated by the PLS-DA 


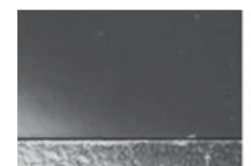

$\mathbf{O h}$

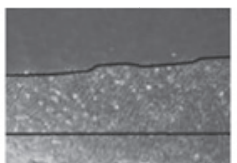

$24 \mathrm{~h}$

A Control

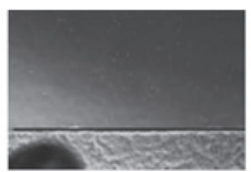

o h

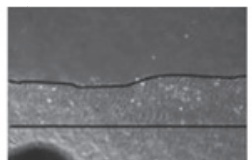

$24 \mathrm{~h}$

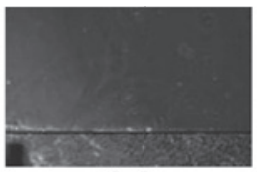

$\mathbf{O h}$

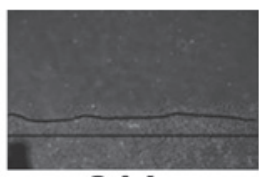

$24 \mathrm{~h}$

$\mathrm{H}_{2} \mathrm{O}_{2} \quad 0.5 \mathrm{mM}$

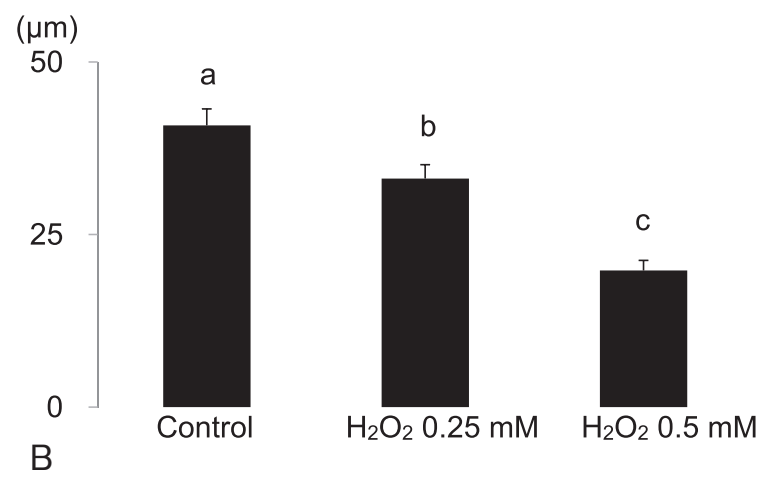

Fig. 1 Effect of different concentrations of $\mathrm{H}_{2} \mathrm{O}_{2}$ on IEC- 6 cell wound restitution

(A) Confluent monolayers of IEC-6 cells were wounded with a scraper, and the cells were then exposed to $\mathrm{H}_{2} \mathrm{O}_{2}$ at $0.25 \mathrm{mM}$ or $\mathrm{H}_{2} \mathrm{O}_{2}$ at $0.5 \mathrm{mM}$ for 24 hours. The denuded areas were photographed immediately after addition of $\mathrm{H}_{2} \mathrm{O}_{2}$ and at 24 hours after wounding. A black dot marker was oriented at the same place for photomicrographs between times. The denuded areas are highlighted by a black line.

(B) The average length of the restitution area is presented. $\mathrm{P}$ values $<0.05$ were considered to indicate significance. Means with different letters are significantly different between groups.

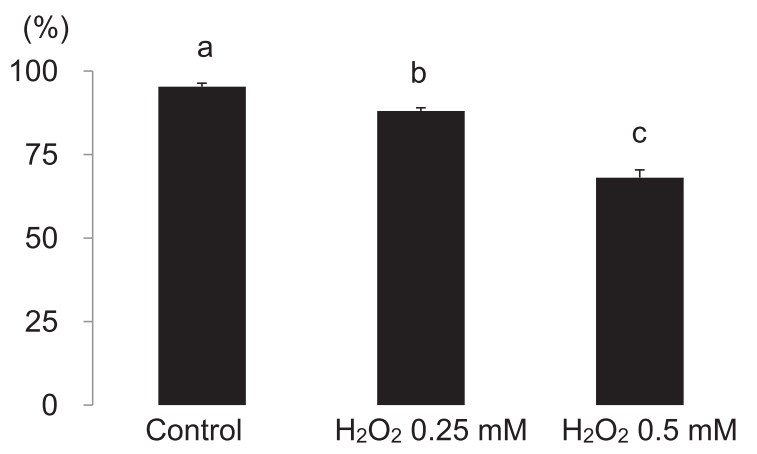

Fig. 2 Effect of different concentrations of $\mathrm{H}_{2} \mathrm{O}_{2}$ on IEC-6 cell viability

The cell viability is presented. Confluent monolayers of IEC-6 cells were exposed to $\mathrm{H}_{2} \mathrm{O}_{2}$ at $0.25 \mathrm{mM}$ or $\mathrm{H}_{2} \mathrm{O}_{2}$ at $0.5 \mathrm{mM}$ for 24 hours. $\mathrm{P}$ values $<0.05$ were considered significant. Means with different letters are significantly different between groups.

algorithm installed in Unscrambler X. On the plot, the color of each dot indicates the class. The classes are as follows: control at 24 hours (blue), $\mathrm{H}_{2} \mathrm{O}_{2} 0.25$ $\mathrm{mM}$ at 24 hours (green), and $\mathrm{H}_{2} \mathrm{O}_{2} \quad 0.5 \mathrm{mM}$ at 24 hours (red). The dots for each class were clearly separated into separate clusters by means of PLS-
DA analysis. This is a 2-dimensional scatter plot of scores for 2 specified factors from PLS regression. The scores plots for factor 1 and factor 2 give information about ${ }^{1} \mathrm{H}$ NMR spectral data, and the class data in the samples and these 2 components summarize the variation of all the data. The 2 values ( $\mathrm{X}$ and $\mathrm{Y}$ ) in the brackets of the axis labels indicate the variance by each corresponding factor. " $X$ " is the spectral variance that was captured by the factor, and " $\mathrm{Y}$ " is the class variance captured by the factor. Spectral variance and class variance were $87 \%$ and $48 \%$, respectively, for factor 1 , and $5 \%$ and $43 \%$, respectively, for factor 2 . Consequently, these 2 factors together described $92 \%(87 \%+5 \%)$ of spectral variance and $91 \%(48 \%+43 \%)$ of class variance.

Corresponding correlation loadings for factor 1 are shown in Figure 3B, and those for factor 2 are shown in Figure 3C. The correlation loadings plot shows the relationship between spectral variables of the samples analyzed, which are responsible for the clustering in the score plots of the samples. 

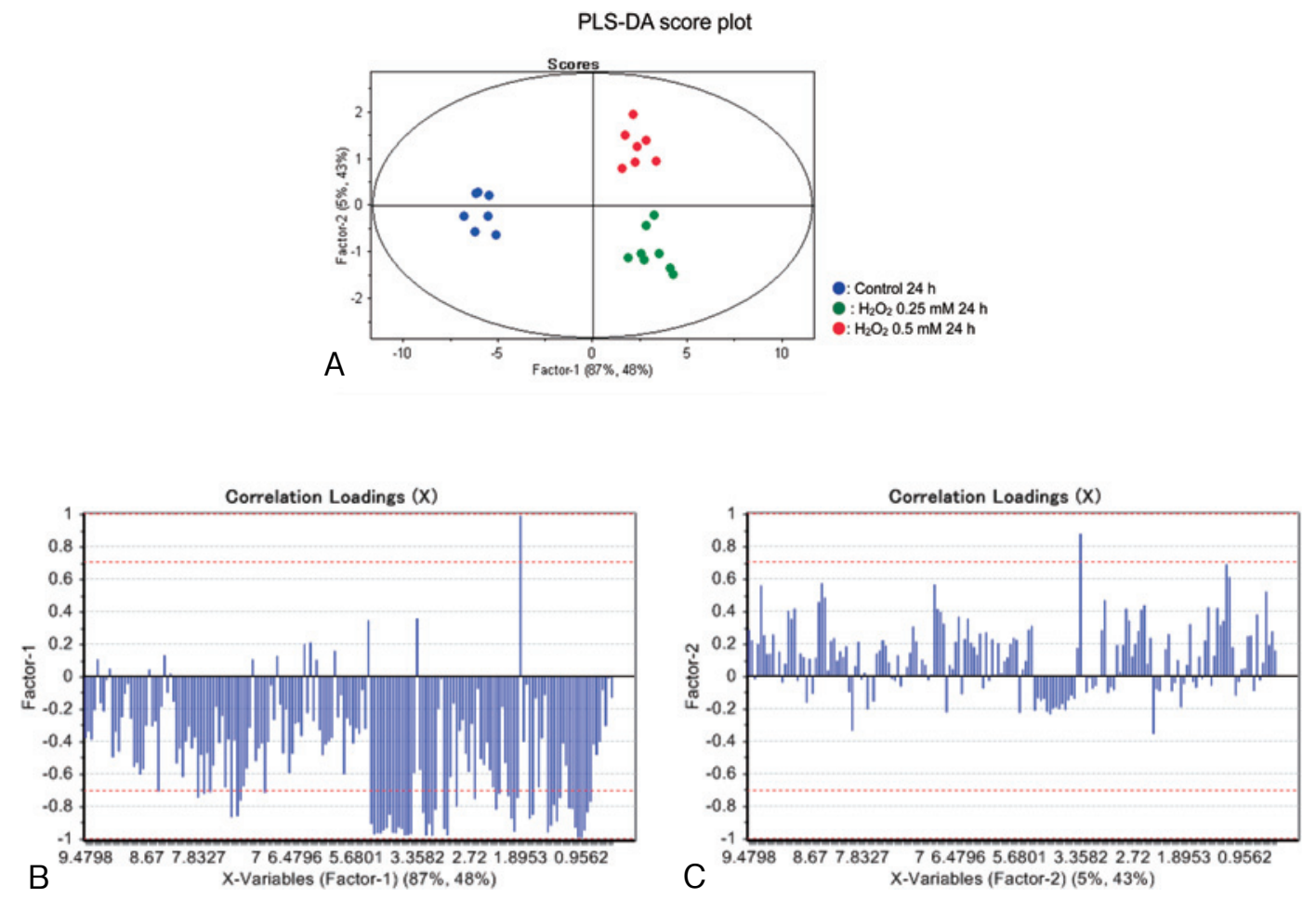

Fig. 3 PLS-DA score plot and correlation loadings of different concentration of $\mathrm{H}_{2} \mathrm{O}_{2}$ on IEC-6 cells

(A) Each dot represents the score of an IEC-6 cell sample calculated with PLS-DA analysis. Classes are delineated as follows: control 24 hours (blue), $\mathrm{H}_{2} \mathrm{O}_{2}$ at $0.25 \mathrm{mM}$ at 24 hours (green), $\mathrm{H}_{2} \mathrm{O}_{2}$ at $0.5 \mathrm{mM}$ at 24 hours. The dots for each class were clearly separated into clusters with PLS-DA analysis.

(B) Corresponding loadings of factor 1 are present.

(C) Corresponding loadings of factor 2 are present.

\section{Experiment 2.}

Effect of different time points of $\mathrm{H}_{2} \mathrm{O}_{2}$ on IEC- 6 cell wound restitution

Restitution was gradually increased by $\mathrm{H}_{2} \mathrm{O}_{2}$ at 0.5 $\mathrm{mM}$ at 6 hours $(4.4 \pm 0.5 \mu \mathrm{m})$, at 12 hours $(13.3 \pm 1.4$ $\mu \mathrm{m})$, and at 24 hours $(19.8 \pm 1.5 \mu \mathrm{m})$ in a timedependent manner, but restitution was significantly suppressed compared with control at each time point: 6 hours $(11.1 \pm 1.2 \mu \mathrm{m}), 12$ hours $(28.0 \pm 1.6 \mu \mathrm{m})$, and 24 hours $(40.8 \pm 3.4 \mu \mathrm{m})$ (Fig. 4).

Effect of different time points of $\mathrm{H}_{2} \mathrm{O}_{2}$ on IEC- 6 cell viability

Cell viability was similar between $\mathrm{H}_{2} \mathrm{O}_{2}$ at $0.5 \mathrm{mM}$ at 6 hours $(90.2 \% \pm 0.5 \%)$ and at 12 hours $(89.5 \% \pm 1.2 \%)$ and was significantly decreased between $\mathrm{H}_{2} \mathrm{O}_{2}$ at 0.5 $\mathrm{mM}$ at 24 hours $(68.4 \% \pm 1.2 \%)$. The viability of cells exposed to $\mathrm{H}_{2} \mathrm{O}_{2}$ at $0.5 \mathrm{mM}$ was significantly different from control at each time point: 0 hours $(97.3 \% \pm$ $0.2 \%), 6$ hours $(97.1 \% \pm 0.9 \%), 12$ hours $(96.6 \% \pm 0.8 \%)$, and 24 hours $(96.6 \% \pm 0.4 \%)$ (Fig. 5).
Visualization with PLS-DA analysis of ${ }^{1} \mathrm{H}$ NMR spectral data of IEC-6 cells at different time points after exposure to $\mathrm{H}_{2} \mathrm{O}_{2}$

The dots for each class were clearly separated into separate clusters by means of PLS-DA analysis. Two-dimensional scatter plots of scores for the 2 specified factors from PLS regression were created. The score plot for factor 1 and factor 2 gives information about ${ }^{1} \mathrm{H}$ NMR spectral data and the class data in the samples, and these 2 components summarize the variation in all of the data.

The PLS-DA score plot for exposure to $\mathrm{H}_{2} \mathrm{O}_{2}$ is shown in Figure 6A. Each dot on the score plot represents the score of factors 1 and 2 of the ${ }^{1} \mathrm{H}$ NMR spectral data of the IEC-6 cell extract calculated with the PLS-DA algorithm that is installed in Unscrambler X. On the plot, the color of each dot indicates the class. The classes are as follows: control at 0 hours (blue), $\mathrm{H}_{2} \mathrm{O}_{2}$ at $0.5 \mathrm{mM}$ at 6 hours (green), $\mathrm{H}_{2} \mathrm{O}_{2}$ at $0.5 \mathrm{mM}$ at 12 hours (orange), and $\mathrm{H}_{2} \mathrm{O}_{2}$ at $0.5 \mathrm{mM}$ at 24 hours (red). The dots of the 

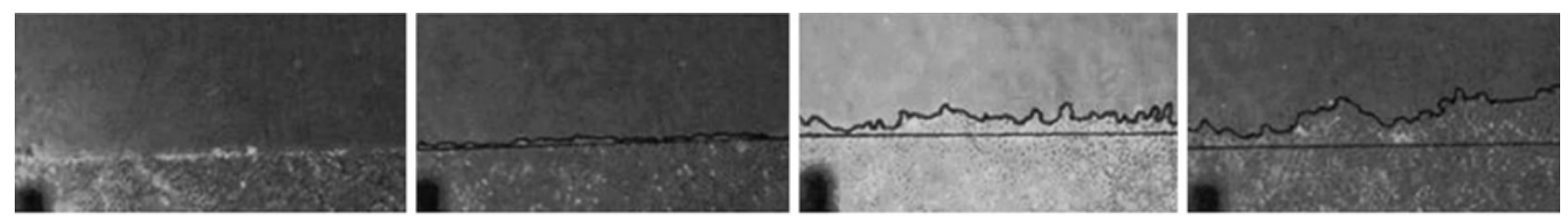

\section{$\mathrm{H}_{2} \mathrm{O}_{2} 0.5 \mathrm{mM} \mathrm{O} \mathrm{h}$}

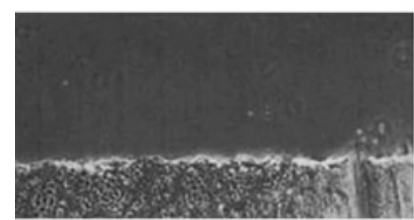

A

\section{Conrtol $\mathbf{O h}$}

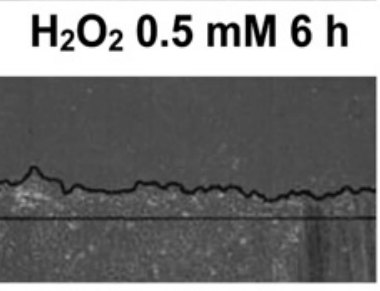

$\mathrm{H}_{2} \mathrm{O}_{2} 0.5 \mathrm{mM} 12 \mathrm{~h}$

$\mathrm{H}_{2} \mathrm{O}_{2} 0.5 \mathrm{mM} 24 \mathrm{~h}$

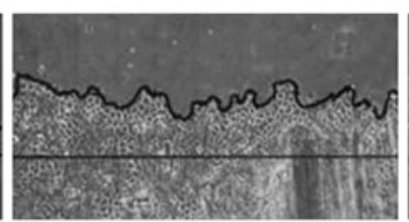

Control
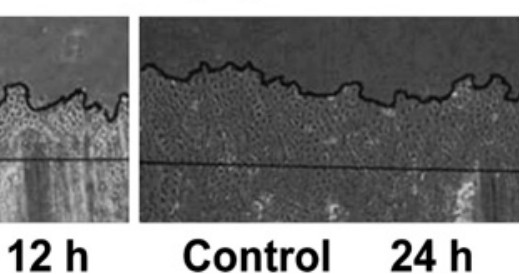

Control

$24 \mathrm{~h}$

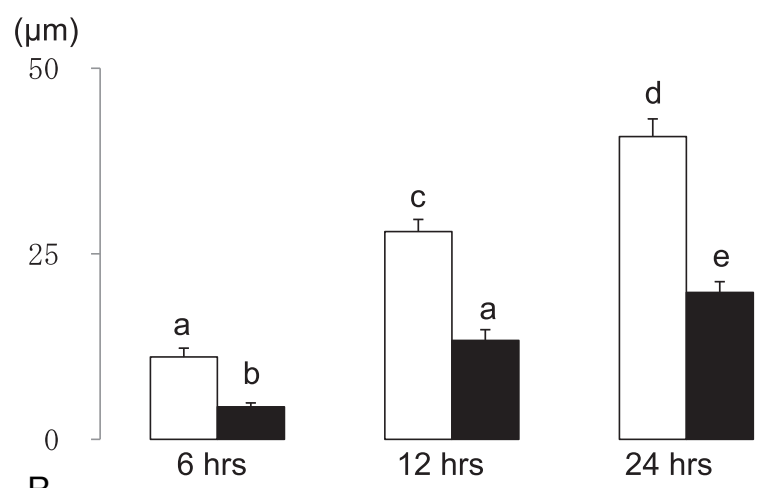

Fig. 4 Effect of different time points of $\mathrm{H}_{2} \mathrm{O}_{2}$ on IEC- 6 cell wound restitution

(A) Confluent monolayers of IEC-6 cells were wounded with a scraper, and the cells were then exposed to $\mathrm{H}_{2} \mathrm{O}_{2}$ at 0.5 $\mathrm{mM}$ for 6 hours, $\mathrm{H}_{2} \mathrm{O}_{2}$ at $0.5 \mathrm{mM} 12$ hours, $\mathrm{H}_{2} \mathrm{O}_{2}$ at $0.5 \mathrm{mM}$ for 24 hours, and without $\mathrm{H}_{2} \mathrm{O}_{2}$ as control. The denuded areas were photographed immediately after addition of $\mathrm{H}_{2} \mathrm{O}_{2}$ or without $\mathrm{H}_{2} \mathrm{O}_{2}$ at 6 , 12, and 24 hours after wounding. A black marker dot is oriented at the same place in photomicrographs between times. The denuded areas are highlighted by a black line.

(B) The average length of the restitution area is presented. $\mathrm{P}$ values 0.05 were considered significant. Means with different letters are significantly different between groups. $\square$ was control and $\boldsymbol{\square}$ was $\mathrm{H}_{2} \mathrm{O}_{2}$.

classes at 6 hours and at 12 hours were not separated into clusters. The dots were clearly distinguished into 3 separate clusters between control, at 6 and 12 hours, and at 24 hours on the score plot calculated with PLS-DA analysis. Spectral variance and category variance were $95 \%$ and $32 \%$, respectively, for factor 1 and $2 \%$ and $28 \%$, respectively, for factor 2 . Consequently, factor 1 and factor 2 together described $97 \%(95 \%+2 \%)$ and $60 \%$ $(32 \%+28 \%)$ of the variation, respectively. Correlation loading of factor 1 is shown in Figure $\mathbf{6 B}$, and that of factor 2 is shown in Figure 6C.

The PLS-DA score plot for exposure to $\mathrm{H}_{2} \mathrm{O}_{2}$ and control is shown in Figures $\mathbf{7 A}$ and $\mathbf{7 B}$. Each dot on the score plot represents the score of factors 1,2 , and 3 of the ${ }^{1} \mathrm{H}$ NMR spectral data of the IEC- 6 cell extract calculated with the PLS-DA algorithm of Unscrambler X. On the plot, the color of each dot indicates the class. The PLS-DA score plot in Figure $\mathbf{7 A}$ is from factors 1 and 2 , and that in Figure $\mathbf{7 B}$ is from factors 1 and 3 . The classes are as follows: control at 0 hours (blue), control at 6 hours (green ring), control at 12 hours (orange ring), control at 24 hours (red ring), $\mathrm{H}_{2} \mathrm{O}_{2}$ at $0.5 \mathrm{mM}$ at 6 hours (green), $\mathrm{H}_{2} \mathrm{O}_{2}$ at $0.5 \mathrm{mM}$ at 12 hours (orange), and $\mathrm{H}_{2} \mathrm{O}_{2}$ at 0.5 $\mathrm{mM}$ at 24 hours (red). The dots of the control class at 0 hours and 24 hours were not separated into clusters (Fig. 7A). The dots of the control at 6 hours and at 12 hours were broadly distinguished into separate clusters but were in different areas from those of control at 0 hours and at 24 hours (Fig. 7A). On the score plot calculated with PLS-DA analysis, 
(\%)

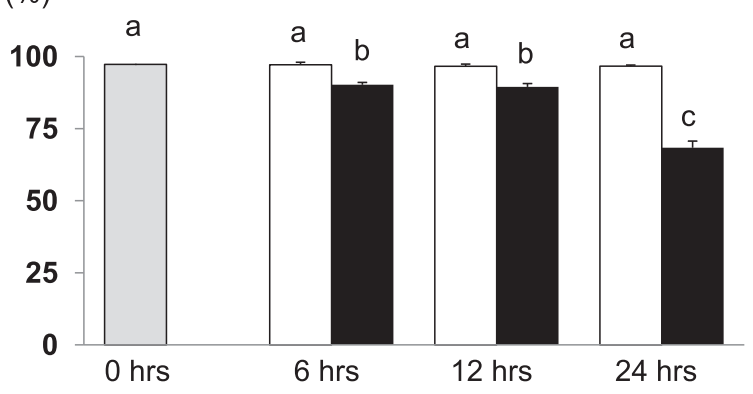

Fig. 5 Effect of different time points of $\mathrm{H}_{2} \mathrm{O}_{2}$ on IEC-6 cell viability

Cell viability is presented. Confluent monolayers of IEC- 6 cells were exposed to $\mathrm{H}_{2} \mathrm{O}_{2}$ at $0.5 \mathrm{mM}$ for 6 hours, $\mathrm{H}_{2} \mathrm{O}_{2}$ at $0.5 \mathrm{mM}$ for 12 hours, or $\mathrm{H}_{2} \mathrm{O}_{2}$ at $0.5 \mathrm{mM}$ for 24 hours. Cell viability was also assessed without $\mathrm{H}_{2} \mathrm{O}_{2}$ as control. $\mathrm{P}$ values $<0.05$ were considered significant. Means with different letters are significantly different between groups. was control and $\boldsymbol{\square}$ was $\mathrm{H}_{2} \mathrm{O}_{2}$. the dots were separated into 5 clusters: control at 0 and 24 hours, control at 6 hours, control at 12 hours, $\mathrm{H}_{2} \mathrm{O}_{2}$ at 6 and 12 hours, and $\mathrm{H}_{2} \mathrm{O}_{2}$ at 24 hours. The dots of control at 0 hour and at 24 hours were not separated into clusters (Fig. 7B). The dots of control at 6 and at 12 hours were not separated into clusters but were in areas different from those of control at 0 hour and at 24 hours (Fig. 7B). The dots of the $\mathrm{H}_{2} \mathrm{O}_{2}$ at 6,12 , and 24 hours were clustered in similar areas but were clearly distinguished from those of the control groups (Fig. 7B). Spectral variance was and category variance were $93 \%$ and $92 \%$, respectively, for factor 1 , and $3 \%$ and $3 \%$, respectively, for factor 2 , and $1 \%$ and $1 \%$, respectively, for factor 3 . Consequently, factors 1 and 2 together described $96 \%(93 \%+3 \%)$ and $95 \%(92 \%+$ $3 \%$ ) of the variation, and factors 1 and 3 together described $94 \%(93 \%+1 \%)$ and $93 \%(92 \%+1 \%)$ of the variation. Correlation loadings of factor 1, 2, and 3
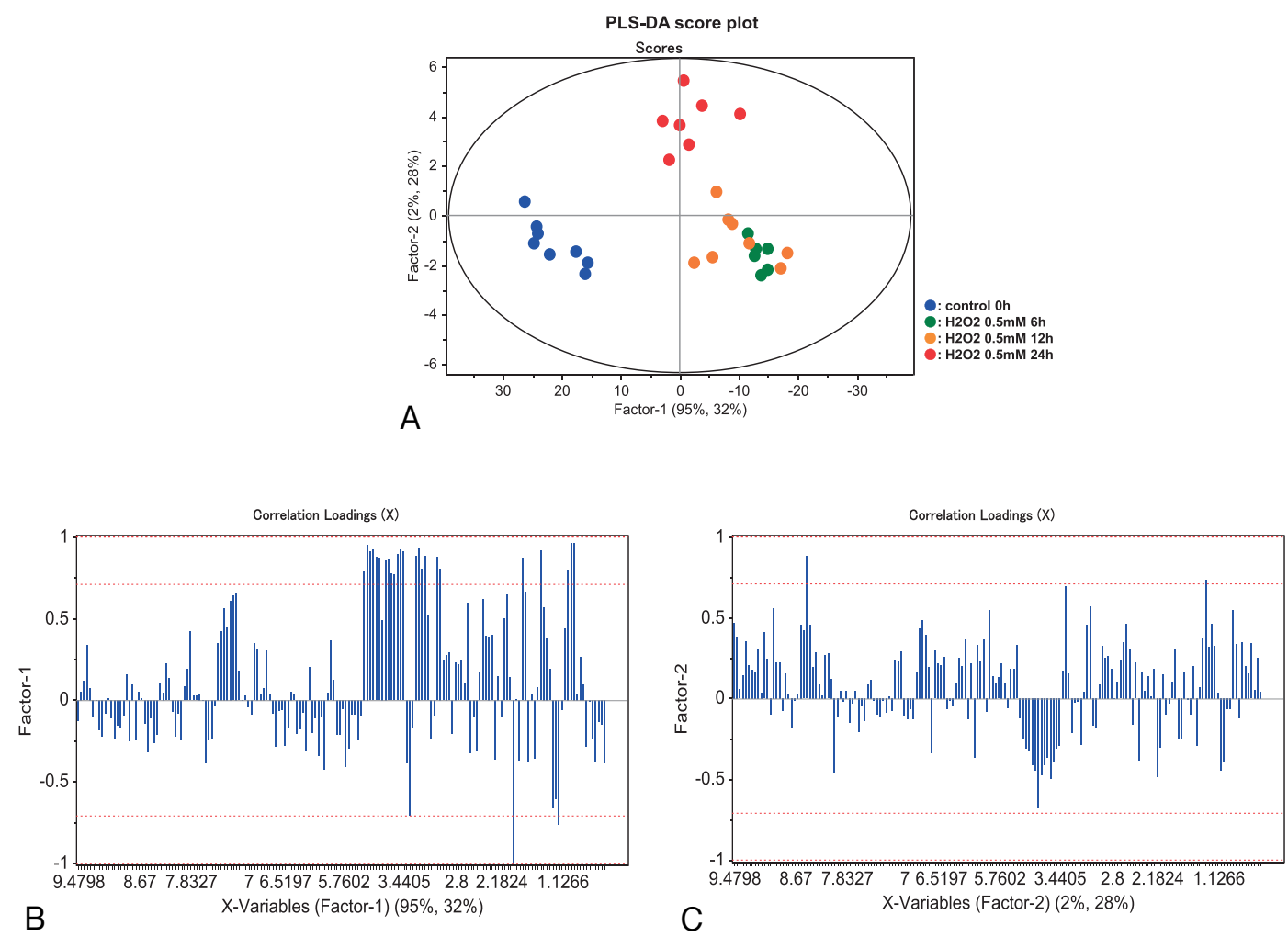

Fig. 6 PLS-DA score plot and correlation loadings of different time points of exposure to $\mathrm{H}_{2} \mathrm{O}_{2} 0.5$ on IEC-6 cells

(A) Each dot represents the score of an IEC-6 cell sample calculated with PLS-DA analysis. Classes are delineated as follows: control at 0 hours (blue), $\mathrm{H}_{2} \mathrm{O}_{2}$ at $0.5 \mathrm{mM}$ at 6 hours (green), $\mathrm{H}_{2} \mathrm{O}_{2}$ at $0.5 \mathrm{mM}$ at 12 hours (orange), and $\mathrm{H}_{2} \mathrm{O}_{2}$ at $0.5 \mathrm{mM}$ at 24 hours (red).

(B) Correlation loadings of factor 1 are presented.

(C) Correlation loadings of factor 2 are presented. 

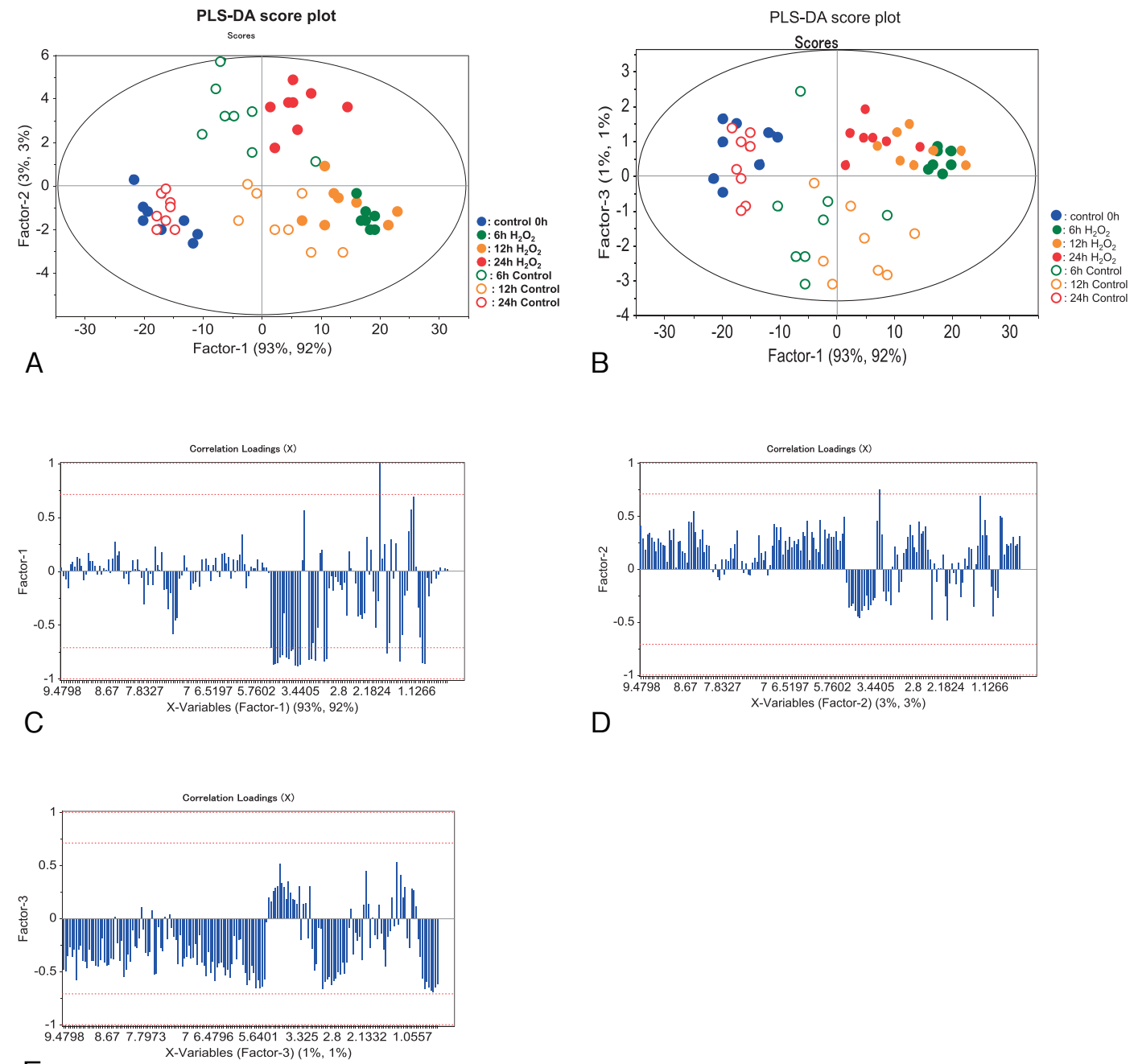

E

Fig. 7 PLS-DA score plot and correlation loadings of different time points of $\mathrm{H}_{2} \mathrm{O}_{2}$ and without $\mathrm{H}_{2} \mathrm{O}_{2}$ as control on IEC-6 cells

(A) Each dot represents the score of an IEC-6 cell sample calculated with PLS-DA analysis for factors 1 and 2. Classes are delineated as follows: control at 0 hours (blue), control at 6 hours (green ring), control at 12 hours (orange ring), control at 24 hours (red ring), $\mathrm{H}_{2} \mathrm{O}_{2}$ at $0.5 \mathrm{mM}$ at 6 hours (green), $\mathrm{H}_{2} \mathrm{O}_{2}$ at $0.5 \mathrm{mM}$ at 12 hours (orange), and $\mathrm{H}_{2} \mathrm{O}_{2}$ at $0.5 \mathrm{mM}$ at 24 hours (red).

(B) Each dot represents the score of an IEC-6 cell sample calculated with PLS-DA analysis for factors 1 and 3. Classes are delineated as follows: control at 0 hours (blue), control at 6 hours (green ring), control at 12 hours (orange ring), control at 24 hours (red ring), $\mathrm{H}_{2} \mathrm{O}_{2}$ at $0.5 \mathrm{mM}$ at 6 hours (green), $\mathrm{H}_{2} \mathrm{O}_{2}$ at $0.5 \mathrm{mM}$ at 12 hours (orange), and $\mathrm{H}_{2} \mathrm{O}_{2}$ at $0.5 \mathrm{mM}$ at 24 hours (red).

(C) Correlation loadings of factor 1 are presented.

(D) Correlation loadings of factor 2 are presented.

(E) Correlation loadings of factor 3 are presented.

are shown in Figures 7C, 7D, and 7E, respectively.

\section{Discussion}

The gut is crucial in the development of acute lung injury and multiple organ dysfunction syndrome after initial injuries, such as major trauma, hemorrhagic shock, severe septic shock, superior mesenteric occlusion, and small intestine transplantation. All these conditions can disturb the splanchnic blood flow and lead to I/R mucosal injury in the gut ${ }^{1}$. Early studies focused on translocation of intestinal flora to the systemic circulation following gut $\mathrm{I} / \mathrm{R}$, with the portal vein as the main cause $\mathrm{e}^{1920}$. 
Although initial animal models offered evidence supporting bacterial translocation, diversion of the mesenteric lymph duct before hemorrhagic shock appears to be attenuated by neutrophil priming, endothelial adhesion, and inflammatory molecular expression in animal models ${ }^{19}$. On the basis of this evidence, the release of bacteria or nonmicrobial factors or both from the gut through the portal vein or the intestinal lymphatic route or both potentiate the development of acute lung injury and multiple organ dysfunction syndrome. The gut-mucosa repair process is absolutely necessary. The initial phase of the repair process is rapid migration of surviving cells over the denuded area to reestablish a continuous epithelial layer. The second phase is proliferation and differentiation of cells to replace the lost cells to build up mucosal villi. The last phase is the functional phase, in which the mucosa returns to providing its normal absorptive function and gut immunity. Although all these phases are significant, the initial phase is especially important for preventing further injury to distant organs.

In this experimental model of intestinal epithelial cell injury, IEC-6 cells were subjected to $\mathrm{H}_{2} \mathrm{O}_{2}$ oxidant stress. Cell viability and wound restitution were examined as visible final phenomenon after exposure to different levels of $\mathrm{H}_{2} \mathrm{O}_{2}$ oxidant stress. Experiment 1 of the present study showed that $\mathrm{H}_{2} \mathrm{O}_{2}$ oxidant stress inhibited wound restitution and decreased cell viability in a dose-dependent manner

(Fig. 1, 2). Experiment 2 of this study also demonstrated that IEC- 6 cells exposed to $\mathrm{H}_{2} \mathrm{O}_{2}$ at 0.5 $\mathrm{mM}$ gradually migrated to the denuded area in a time-dependent manner, inhibited wound restitution compared with control, and decreased cell viability (Fig. 4, 5). Many investigators have subjected intestinal epithelial cells to $\mathrm{H}_{2} \mathrm{O}_{2}$ oxidant stress and showed similar cell damage ${ }^{22-25}$. Studying cell damage produced by various degrees of $\mathrm{H}_{2} \mathrm{O}_{2}$ oxidant stimuli can provide insight into molecular biological mechanisms of the response to stress.

We have also investigated cyclooxygenase (COX)-2 messenger RNA levels as a stress marker in our model. Levels of COX-2 messenger RNA were significantly higher in cells exposed to $\mathrm{H}_{2} \mathrm{O}_{2}$ at 0.25 $\mathrm{mM}$ or $0.5 \mathrm{mM}$ than in control cells (data not shown).
Although many stress markers for evaluating oxidative stress have been proposed, portions of the molecular pathways have gradually been clarified. However, numerous molecular pathways are activated at the same time and interact with each other via stimuli, and different stimuli lead to different molecular pathways. Thus, pursuing all pathways is extremely difficult. We believe that the most important indicator is cell status, which reflects cell viability and cell growth. We believe that evaluation methods can still be greatly improved.

Recent advances in systems biology have allowed for the study and characterization of genes, transcripts, proteins, and metabolites on a global level. Pattern recognition analysis of NMR spectra has been applied to global metabolic studies ${ }^{26,27}$.

In the present study, differences in oxidant injury were successfully visualized in IEC-6 cells exposed to different concentrations of $\mathrm{H}_{2} \mathrm{O}_{2}$ using the chemometrics technique to interpret the NMR data of samples. Although the classes could not be separated with unsupervised principal components analysis $^{28}$, they were clearly separated with supervised PLS-DA. Score plots generated with PLSDA methods can provide a visual representation of information-rich spectral data by means of dimensionality reduction ${ }^{29}$. A score plot shows biological samples clustering into either similar or different groups. The closer the dots are in the samples in the score plot, the more similar they are with respect to the 2 components concerned. On the other hand, dots that are far away from each other are different from each other. In the present study the PLS-DA score plot (Fig. 3A) showed a clear separation between the different classes. The spectral variance of factor 1 was $87 \%$, and that of factor 2 was $5 \%$. Factor 1 contributed to separation with or without $\mathrm{H}_{2} \mathrm{O}_{2}$. Factor 2 contributed to important separations between exposure to different concentrations of $\mathrm{H}_{2} \mathrm{O}_{2}$. These combined attributes explain $92 \%$ of the variation in Figure 3A. Similarly, the PLS-DA score plot in Figure $\mathbf{6 A}$ shows 3 clusters clearly separated between time differences of exposure to $\mathrm{H}_{2} \mathrm{O}_{2}$. Score plots for 6 and 12 hours' exposure were nearby, but score plots for 24 hours' exposure were clustered in a different area (Fig. 
6A).

The PLS-DA score plot combining all control groups and $\mathrm{H}_{2} \mathrm{O}_{2}$ groups are shown in Figures 7A and 7B. The score plot of Figure 7A, which was from factors 1 and 2, contributed to sufficient cluster separation. However, separation was unclear between control at 6 hours and 12 hours and $\mathrm{H}_{2} \mathrm{O}_{2}$ at 6 and 12 hours. The score plot of Figure 7B, which was from factors 1 and 3, contributed to a clear separation with or without $\mathrm{H}_{2} \mathrm{O}_{2}$. Figure 7B shows superior separation between the control groups and $\mathrm{H}_{2} \mathrm{O}_{2}$ groups. The PLS-DA score plot in Figure 6A shows a spectral variance of $97 \%$ (95\% for factor 1 and $2 \%$ for factor 2), that in Figure $\mathbf{7 A}$ shows a spectral variance of $96 \%$ (93\% for factor 1 and $3 \%$ for factor 2), and that in Figure 7B shows a spectral variance of $94 \%$ (93\% for factor 1 and $1 \%$ for factor 3). The PLS-DA score plot in Figure $\mathbf{6 A}$ shows a category variance of $61 \%$ ( $32 \%$ for factor 1 and $28 \%$ for factor 2), that in Figure $\mathbf{7 A}$ shows a category variance of $95 \%$ (92\% for factor 1 and $3 \%$ for factor 2), and that in Figure 7B shows a category variance of $93 \%$ (92\% for factor 1 and $1 \%$ for factor 3). All these PLS-DA score plots successfully showed clear cluster separation. Correlation loadings in Figures 6B, 7B, and 7C showed good separation of many spectral-region-related clusters in these PLS-DA score plots. The IEC- 6 cells exposed to $\mathrm{H}_{2} \mathrm{O}_{2}$ showed dramatically changed cellular status, which included molecular changes, intermolecular forces, structural changes, and metabolic changes. Indeed, NMR spectra reveal whole cellular information that contains these changes. We speculate that our use in the present study of whole NMR spectra data rather than several assigned peaks allowed us to accurately reveal cell status. We successfully visualized cell phenomena, such as cell viability and restitution, using PLS scores calculated from whole NMR spectral data.

In summary, pattern recognition of NMR spectral data using a supervised PLS-DA method clearly visualized differences in oxidant injury in IEC-6 cells exposed to $\mathrm{H}_{2} \mathrm{O}_{2}$. With this method it is possible to evaluate cellular status, such as cell viability and cell growth, of intestinal epithelial cell extracts under oxidative stress. In addition, this method is useful for further elucidating complicated pathophysiology.

Conflict of Interest: The authors declare that they have no conflict of interest.

Acknowledgements: The authors especially thank Ms. Kaori Okihara, Ms. Tomoko Konta, Mr. Hideyuki Morikawa, Mr. Hideki Muraki, and Dr. Tsuyoshi Moriyama for their work on sample preparation, acquisition of ${ }^{1} \mathrm{H}$ NMR data, and support of data analysis to complete this research.

\section{References}

1. Hassoun HT, Kone BC, Mercer DW, et al: Postinjury multiple organ failure: the role of the gut. Shock 2001; 15: 1-10.

2. Yanagida $\mathrm{T}$, Tsushima J, Kitamura $\mathrm{Y}$, et al.: Oxidative stress induction of DJ-1 protein in reactive astrocytes scavenges free radicals and reduces cell injury. Oxid Med Cell Longev 2009; 2: 36-42.

3. Choi EJ, Oh HM, Na BR, et al.: Eupatilin protects gastric epithelial cells from oxidative damage and down-regulates genes responsible for the cellular oxidative stress. Pharm Res 2008; 25: 1355-1364.

4. Quaroni A, Wands J, Trelstad RL, et al.: Epithelioid cell cultures from rat small intestine. Characterization by morphologic and immunologic criteria. J Cell Biol 1979; 80: 248-265.

5. Silver K, Desormaux A, Freeman LC, et al: Expression of pleiotrophin, an important regulator of cell migration, is inhibited in intestinal epithelial cells by treatment with non-steroidal anti-inflammatory drugs. Growth Factors 2012; 30: 258-266.

6. Rao JN, Platoshyn O, Golovina VA, et al.: TRPC1 functions as a store-operated $\mathrm{Ca} 2+$ channel in intestinal epithelial cells and regulates early mucosal restitution after wounding. Am J Physiol Gastrointest Liver Physiol 2006; 290: G782-792.

7. Sturm A, Dignass AU: Epithelial restitution and wound healing in inflammatory bowel disease. World J Gastroenterol 2008; 14: 348-353.

8. Nishimura S, Takahashi M, Ota S, et al.: Hepatocyte growth factor accelerates restitution of intestinal epithelial cells. J Gastroenterol 1998; 33: 172-178.

9. Basson MD: In vitro evidence for matrix regulation of intestinal epithelial biology during mucosal healing. Life Sci 2001; 69: 3005-3018.

10. Martineau E, Tea I, Loaëc G, et al.: Strategy for choosing extraction procedures for NMR-based metabolomic analysis of mammalian cells. Anal Bioanal Chem 2011; 401: 2133-2142.

11. Want E: Challenges in applying chemometrics to LCMS-based global metabolite profile data. Bioanalysis 2009; 1: 805-819.

12. Goke MN, Schneider M, Beil W, Manns MP: Differential glucocorticoid effects on repair mechanisms and NF-kappaB activity in the intestinal epithelium. Regul Pept 2002; 105: 203-214. 
13. Dignass AU, Podolsky DK: Cytokine modulation of intestinal epithelial cell restitution: central role of transforming growth factor beta. Gastroenterology 1993; 105: 1323-1332.

14. Bai J, Cederbaum AI: Cycloheximide protects HepG2 cells from serum withdrawal-induced apoptosis by decreasing p53 and phosphorylated p53 levels. J Pharmacol Exp Ther 2006; 319: 1435-1443.

15. Yoshioka $\mathrm{Y}$, Matsuda T, Nakano $\mathrm{H}$, et al.: In vitro 1H-NMR spectroscopic analysis of metabolites in fast and slow twitch muscles of young rats. Magn Reson Med Sci 2002; 1: 7-13.

16. Folch J, Lees M, Stanley GH: A simple method for the isolation and purification of total lipids from animal tissues. J Biol Chem 1957; 226: 497-509.

17. Wold S, Sjostrom M, Eriksson L: PLS-regression a basic tool of chemometrics. Chemometr Intell 2008; 58: 109-130.

18. Esbensen KH, Guvot D, Westad F, et al.: Multivariate Data Analysis, $5^{\text {th }}$ edition. 2010; CAMO Software.

19. Deitch EA, Bridges RM: Effect of stress and trauma on bacterial translocation from the gut. J Surg Res 1987; 42: 536-542.

20. Sori AJ, Rush BF, Lysz TW, et al.: The gut as source of sepsis after hemorrhagic shock. Am J Surg 1988; 155: $187-192$.

21. Magnotti LJ, Upperman JS, Xu DZ, et al.: Gutderived mesenteric lymph but not portal blood increases endothelial cell permeability and promotes lung injury after hemorrhagic shock. Ann Surg 1998; 228: $518-527$.

22. Takada M, Otaka M, Takahashi T, et al.: Overexpression of a $60-\mathrm{kDa}$ heat shock protein enhances cytoprotective function of small intestinal epithelial cells. Life Sci 2010; 86: 499-504.

23. Shoji H, Oguchi S, Shinohara K, et al.: Effects of ironunsaturated human lactoferrin on hydrogen peroxide-induced oxidative damage in intestinal epithelial cells. Pediatr Res 2007; 61: 89-92.

24. Gu BH, Minh NV, Lee SH, et al.: Deoxyschisandrin inhibits H2O2-induced apoptotic cell death in intestinal epithelial cells through nuclear factorkappaB. Int J Mol Med 2010; 26: 401-406.

25. Song J, Li J, Lulla A, et al.: Protein kinase D protects against oxidative stress induced intestinal epithelial cell injury via Rho/ROK/PKC-delta pathway activation. Am J Physiol Cell Physiol 2006; 290: C1469-C1476.

26. Nicholson JK, Lindon JC, Holmes E: “Metablomics": understanding the metabolic responses of living systems to pathophysiological stimuli via multivariate statistical analysis of biological NMR spectroscopic data. Xenobiotica 1999; 29: 1181-1189.

27. Kawaguchi H, Hirakawa K, Miyauchi K, Koike K, Ohno Y, Sakamoto A: Pattern recognition analysis of proton nuclear magnetic resonance spectra of brain tissue extracts from rats anesthetized with propofol or isoflurane. PLoS One 2010; 5: e11172.

28. Nakata K, Sato N, Asakura T, et al:: Pattern recognition using ${ }^{1} \mathrm{H}-\mathrm{NMR}$ of the intestinal epithelial cell (IEC-6) under oxidative stress. Shock 2010; 33 (suppl 1): 36.

29. Barker M, Rayens W: Partial least squares for discrimination. J Chemometrics 2003; 17: 166-173.

(Received, April 30, 2013)

(Accepted, January 6, 2014) 